CHINESE JOURNAL OF GEOPHYSICS Vol.52, No.2, 2009, pp: 451 460

\title{
OBSERVATION AND THEORETICAL ANALYSIS FOR THE SAND-WAVES MIGRATION IN THE NORTH GULF OF THE SOUTH CHINA SEA
}

\author{
LIN Mian ${ }^{1}$, FAN Feng-Xin ${ }^{2}$, LI Yong ${ }^{1}$, YAN Jun ${ }^{2}$, \\ JIANG Wen-Bin ${ }^{1}$, GONG De-Jun ${ }^{2}$ \\ 1 Institute of Mechanics, Chinese Academy of Sciences, Beijing 100190, China \\ 2 Institute of Oceanology, Chinese Academy of Sciences, Qingdao 266071, China
}

\begin{abstract}
According to the ocean environmental characteristics of the northern gulf in the South China Sea, a quasi-3D mechanic model has been built up for simulating the small-scale sandwaves migration in the sea. Based on the submarine micro-geomorphic observation, the small-scale sandwaves migrations during 15 months have been simulated. The calculation results are in good agreement with the observation in the groove of the sand ridge, but not in the crest. It is indicated that this mechanic model can be used to predict the migration of the small-scale sandwaves dominated by bed load. The results are of great significance for designing submarine pipeline routes.
\end{abstract}

Key words The northern gulf of the South China Sea, Small-scale sandwaves, Quasi-3D mechanic model, Submarine micro-geomorphic data

\section{INTRODUCTION}

To know the submarine sandwaves migration and predict the bottom dynamic features are essential for designing oil pipeline routes. Within the northern gulf of the South China Sea, where the pipelines of the Dongfang 1-1 gas field just cross through, the sandwaves are extremely active. The submarine micro-geomorphic explorations have shown that the pipelines, which were laid on the bottom initially, have been suspended with several segments due to the sandwaves migration. The cases may result in the pipelines rupture. Thus, the knowledge about sandwaves migration is the focused concern of engineers. Meanwhile, to study the depositional mechanisms of the micro-topography is also concerned by scientists in earth science community.

It is a common knowledge that the tidal currents drive sandwaves moving ${ }^{[1 \sim 6]}$. At first, the currents are reduced to uniflow, but the results are far larger than measured values ${ }^{[7 \sim 10]}$. Hulscher ${ }^{[11 \sim 13]}$ suggested a circular tidal model to explain the forming mechanism for the large-scale sandwaves. To recur to the concept, some researches investigate the sandwaves migration recently ${ }^{[14 \sim 18]}$. However the model only is validated for the large-scale sandwaves. As known, there are small-scale sandwaves in some seas (the wavelengths are only tens of meters). Obviously, the circular tidal model can not be used to describe the small-scale sandwaves migration. Therefore to set up an appropriate model is the key. Taking the small-scale sandwaves covering the northern gulf of the South China Sea as an example we study the problem in this paper.

Firstly, according to the environment characteristics in the sea, a quasi-three-dimensional physical model for small-scale sandwaves is constructed. Then the migration rules in the sea are analyzed by comparing with observational data. Finally the scope of application of the model is discussed.

\section{SURVEY IN NORTHERN GULF OF THE SOUTH CHINA SEA}

In the middle and later 1980s, many counties, such as the US, UK and Canada, began to evaluate seafloor dynamic processes using the multi-beam system. In recent years our country also has carried out the work in this field. Since 2004, the scientists of the Chinese Academy of Sciences have surveyed the submarine microgeomorphic features in the northern gulf of the South China Sea several times and the survey range covers from

E-mail: linmian@imech.ac.cn 
$\left(18^{\circ} 50.75^{\prime} \mathrm{N}, 108^{\circ} 15.45^{\prime} \mathrm{E}\right)$ to $\left(18^{\circ} 52.96^{\prime} \mathrm{N}, 108^{\circ} 18.49^{\prime} \mathrm{E}\right)$. We choose the region from $\left(18^{\circ} 51.84^{\prime} \mathrm{N}, 108^{\circ} 16.23^{\prime} \mathrm{E}\right)$ to $\left(18^{\circ} 52.73^{\prime} \mathrm{N}, 108^{\circ} 17.81^{\prime} \mathrm{E}\right)$ as the study area, which covers more than 30 sandwaves with the average wavelengths of $33 \mathrm{~m}$ and the average heights less than $1.2 \mathrm{~m}$ (see Fig. 1). The sandwaves belong to the kind of small-scale sandwaves. There is a sand ridge through the study area and the sandwaves are seated on the sand ridge and grooves.

The South China Sea, situated at the joint of the Indian Ocean and Pacific Ocean, is surrounded by the mainland of China, Vietnam, Philippine and Borneo. The Asian monsoon and Australia monsoon occur annually and form the ocean circulations. According to meteorological and hydrological data ${ }^{[19]}$, the wind orientation is S-SSW from May to August, with average velocity of $7.19 \mathrm{~m} / \mathrm{s}$, but the wind orientation is NE from October to next March, with average velocity of $5.83 \mathrm{~m} / \mathrm{s}$. The wind orientation reverses during April and September, respectively. The principal tidal component is of diurnal tide. In addition, the average water depth in the study area is $42 \mathrm{~m}$, the water wave height is around $<1.2 \mathrm{~m}$, the wave period around $3.1 \sim 5.0 \mathrm{~s}$, and the wave length between 15 39 m. Referring to the above environmental parameters, we will propose a physical model for the small-scale sandwaves in next section.

(a)

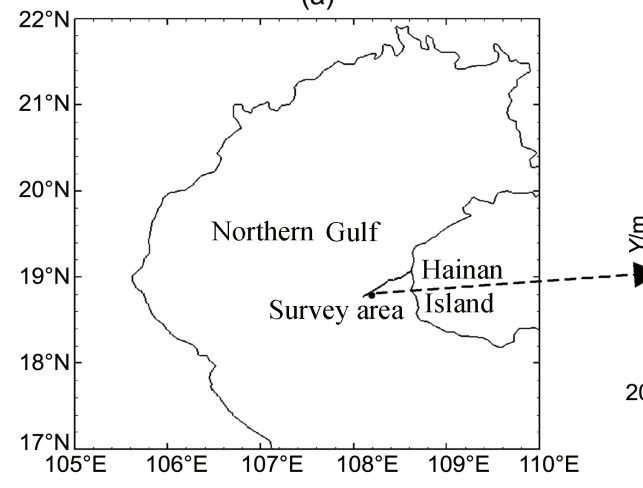

(b)

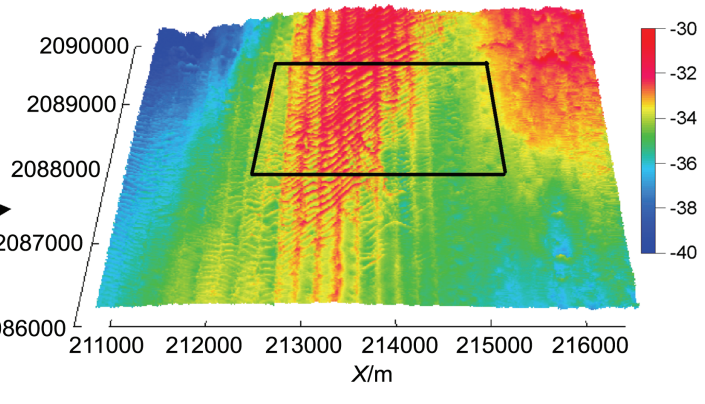

Fig.1 The survey area

(a) The round spot shows survey area;(b) The square is the study area in this paper.

\section{THE BASIC PHYSICAL MODEL}

According to the marine situation of the study area, we consider the influence of tide, wind and water wave on the sandwaves generating, developing and moving simultaneously. Their velocities are the key parameters. With reference to the marine parameters near seabed, we estimate the average tidal velocity of $0.2 \mathrm{~m} / \mathrm{s}$, winddriven current velocity about $0.1 \mathrm{~m} / \mathrm{s}$ and the wave mass transport velocity around $3.1 \times 10^{-6} \mathrm{~m} / \mathrm{s}$. It is clear that the influence of water wave is very small and negligible except for storm surges, typhoon and other extreme sea conditions. Therefore the tidal and wind-driven current should be the main driving forces and their contributions are studied in this paper.

The average wavelength of sandwaves is about $33 \mathrm{~m}$ in the study area, less than the tidal wavelengths by two orders of magnitude. Thus we consider that the sandwaves are generated due to the flow layer instability near the seabed instead of the circular tidal wave action. Using the shallow water wave model to describe water flow field, we have ${ }^{[20]}$ :

$$
\begin{aligned}
& \frac{\partial \xi}{\partial t}+\frac{\partial}{\partial x}(H u)+\frac{\partial}{\partial y}(H v)=0, \\
& \frac{\partial u}{\partial t}+u \frac{\partial u}{\partial x}+v \frac{\partial u}{\partial y}=f v-g \frac{\partial \xi}{\partial x}+\varepsilon \nabla^{2} u-\frac{1}{\rho H} \tau_{x}^{\mathrm{b}}, \\
& \frac{\partial v}{\partial t}+u \frac{\partial v}{\partial x}+v \frac{\partial v}{\partial y}=-f u-g \frac{\partial \xi}{\partial y}+\varepsilon \nabla^{2} v-\frac{1}{\rho H} \tau_{y}^{\mathrm{b}},
\end{aligned}
$$


where $\xi$ is the free surface elevation; $H$ is the undisturbed water depth; $u$ and $v$ are the velocity components along the longitude and the latitude; $g$ is the acceleration of gravity; $\varepsilon$ is the eddy viscosity coefficient; $\tau_{x}^{\mathrm{b}}$ and $\tau_{y}^{\mathrm{b}}$ are the shear stresses at the bottom in the $x$ and $y$ directions; and $f$ is the Coriolis coefficient.

The study area is seated in the continental shelf with a constant slope in the northern gulf of the South China Sea. The circulation current driven by the monsoons in the vertical plane near the seabed is written as $^{[21]}$ :

$$
\left\{\begin{array}{l}
u(z)=\left(\frac{U_{* c}}{\kappa} \ln \left(\frac{z}{k_{\mathrm{b}}}\right)+8.5 U_{* c}\right) \cos \gamma \\
v(z)=\left(\frac{U_{* c}}{\kappa} \ln \left(\frac{z}{k_{\mathrm{b}}}\right)+8.5 U_{* c}\right) \sin \gamma
\end{array}\right.
$$

where $U_{* c}=\sqrt{\tau_{\mathrm{c}} / \rho_{\mathrm{f}}}, \tau_{\mathrm{c}}=c_{\mathrm{d}} R|R|, R=\sqrt{Q^{2} c_{\mathrm{ds}} \rho_{\mathrm{a}} \cos \alpha / c_{\mathrm{d}} \rho_{\mathrm{f}} \cos \gamma}$ is the slip velocity at the bottom, $Q$ is the monsoon speed and $\alpha$ is the monsoon orientation deduced by meteorological and hydrological data; $\rho_{\mathrm{a}}$ and $\rho_{\mathrm{f}}$ denote the density of air and water respectively; $c_{\mathrm{ds}}$ is the surface drag coefficient; $c_{\mathrm{d}}$ is a drag coefficient; and $\gamma$ represents the slip velocity direction determined by the following formula:

$$
\begin{aligned}
& \left(\sqrt{\frac{f \varepsilon(\rho \cos \alpha \cos \gamma)}{\left(\rho_{\mathrm{a}} c_{\mathrm{d}} c_{\mathrm{ds}}\right)}}\right) \sin \gamma(\cosh H \sqrt{2 f / \varepsilon}-\cos H \sqrt{2 f / \varepsilon}) \\
& =2 Q \cos \gamma[\sin (\alpha-\pi / 4) \sinh H \sqrt{f / 2 \varepsilon} \cos H \sqrt{f / 2 \varepsilon}-\cos (\alpha-\pi / 4) \cosh H \sqrt{f / 2 \varepsilon} \sin H \sqrt{f / 2 \varepsilon}] \\
& -Q \cos \alpha[\sin (\alpha-\pi / 4) \sinh H \sqrt{2 f / \varepsilon}-\cos (\gamma-\pi / 4) \sin H \sqrt{2 f / \varepsilon}]
\end{aligned}
$$

The sandwave migrations are controlled dominantly by the bed load transport mode. Two kinds of sediment-transport models are considered:

$$
\begin{array}{ll}
\text { Model 1: } & \frac{\partial \eta}{\partial t}+\frac{\partial q_{x}}{\partial x}+\frac{\partial q_{y}}{\partial y}=0 \\
\text { Model 2: } & \frac{\partial \eta}{\partial t}+\frac{\partial}{\partial x}\left(q_{x}-\lambda_{\mathrm{m}}\left|q_{x}\right| \frac{\partial \eta}{\partial x}\right)+\frac{\partial}{\partial y}\left(q_{y}-\lambda_{\mathrm{m}}\left|q_{y}\right| \frac{\partial \eta}{\partial y}\right)=0
\end{array}
$$

where $\boldsymbol{q}=\left\{\begin{array}{ll}B \sqrt{d}\left(|\boldsymbol{u}| / u_{0}\right)^{n}\left(\boldsymbol{u}-u_{0}\right)(d / \alpha|h|)^{1 / m} & |\boldsymbol{u}|>u_{0} \\ 0 & |\boldsymbol{u}| \leq u_{0}\end{array}\right.$, here $u_{0}=3.6 d^{1 / 3}(0.7|h|)^{1 / 10}, \eta$ is the bottom level; $\boldsymbol{u}$ is the water particle velocity near bottom; $d$ is the grain average diameter; and $h$ is the sandwaves height. It is obvious that the effect of water depth on the bed load sediment is just considered in the model 1 and another factor of bed slope $\lambda$ is combined in the model 2. In the next section, we will calculate the sandwaves migration due to the interaction of the tidal current and the wind-driven current and discuss the model's reasonability.

\section{CALCULATION RESULTS}

The survey data obtained in July 2004 and October 2005 are used for calculation. For the convenience of analysis, the study area is divided into three zones $\mathrm{A}, \mathrm{B}$ and $\mathrm{C}$ (Fig. 2). The zone $\mathrm{A}$ and zone $\mathrm{C}$ are located on the bilateral grooves of the ridge and the zone $\mathrm{B}$ on the ridge back.

First of all, we simulate the entire tidal current of the northern gulf in the South China Sea. At the mouth and strait of the Hainan Island, the open boundary condition is given, namely the horizontal velocity component along the open boundary and the partial derivative of the vertical velocity component are zero.

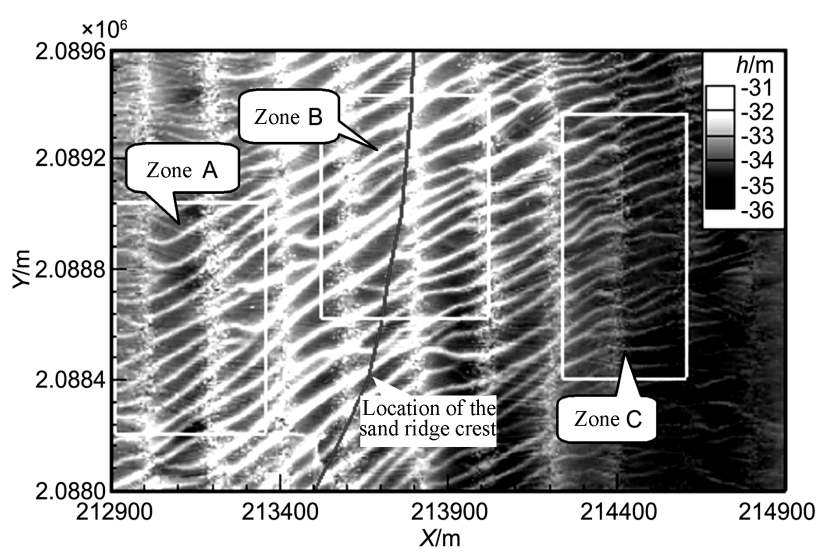

Fig. 2 Positions of zone A, zone B and zone $\mathrm{C}$ in the study area 

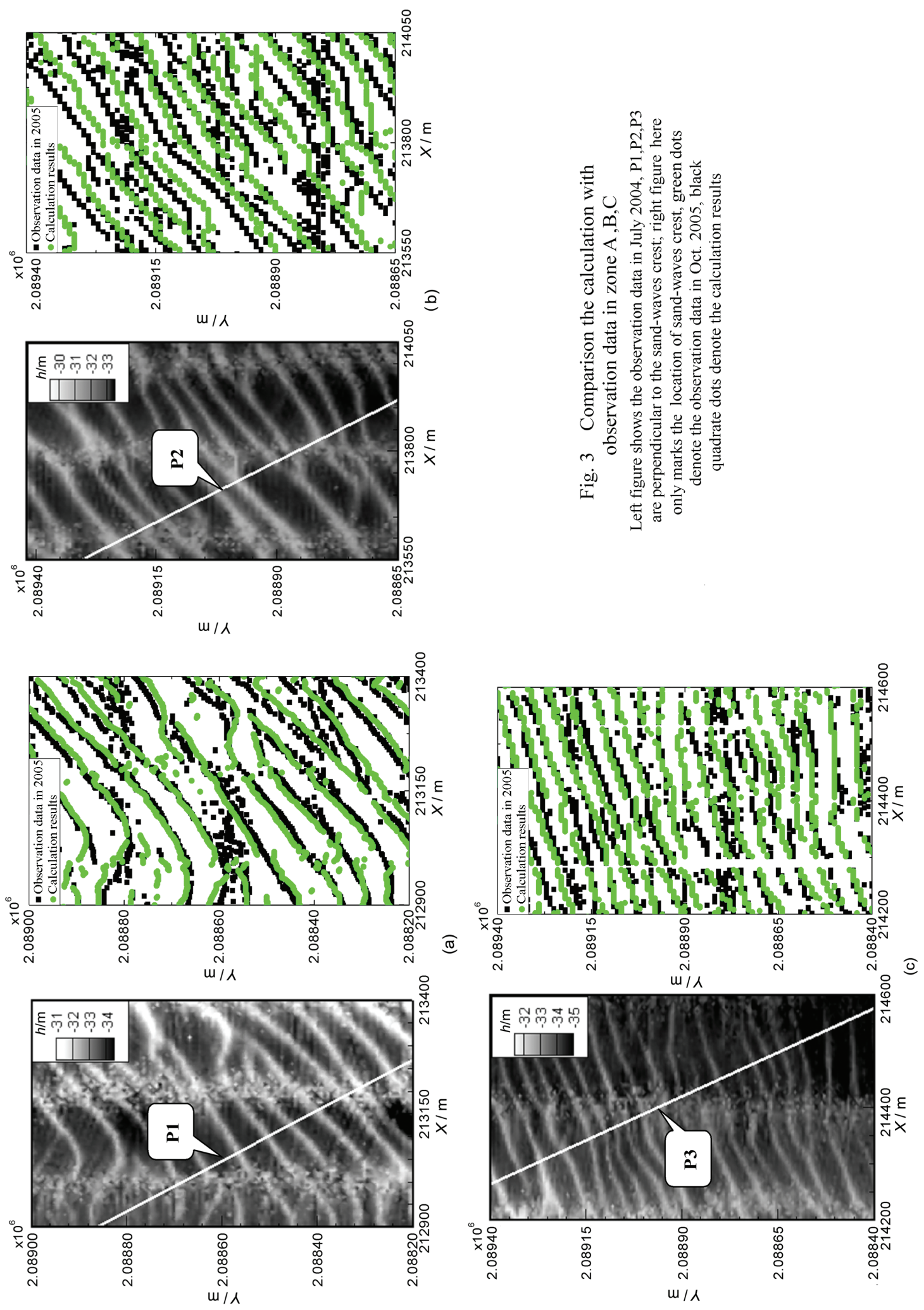
Water level at the open boundary is obtained by the three major constituents K1, O1 and M2. The value of bottom friction coefficient satisfies $(2.6-H / 200) \times 10^{-3}$. To ensure the calculation to converge, a ramp function is used to smooth the transition from a cold start. The water levels increase gradually from zero at first several steps and are stable after four tidal cycles. The amplitude and epoch of each node are determined using harmonic analysis for the whole northern gulf. Then the boundary conditions for the small region (that is the study area) are determined by interpolating the value of the northern gulf, and the flow field for the small region can be calculated.

To refer the multibeam bathymetric data in July 2004 as the initial bottom boundary, the variation of the sandwaves configurations with time can be simulated by coupling water flow field with the sediment transportation equation. The physical calculating time covers 15 months from 1st June 2004 to 1st Octorber 2005. Fig. 3 shows the prediction results of sandwavess positions in Octorber 2005 and the survey data in June 2004 and in Octorber 2005 are also plotted in the figure. It indicates that numerical results are in good agreement with the observed data in zones A and C, but with the significant difference in zone B. We will discuss the reason later.

Two basic parameters are defined firstly: symmetry index $\alpha=\left(L_{1}-L_{2}\right) / L$ and steep ratio $\beta=$ $\max \left(h / L_{1}, h / L_{2}\right)$, as shown in Fig. 4 , here $L=L_{1}+L_{2}$ and $h$ are the average wavelength and height of sandwaves, respectively. $L_{1,2}$ represents the projections of stoss (lee) side. In general, the lee side of a sandwave means its moving oritentation, that is to say, if $\alpha$ is positive, the sandwaves move toward right, and if $\alpha$ is negtive, the sandwaves toward left. In order to analyze the relation between sandwaves features and migration conveniently, three straight lines P1, P2 and P3 perpendicular to the sandwaves crests are drawn in zones

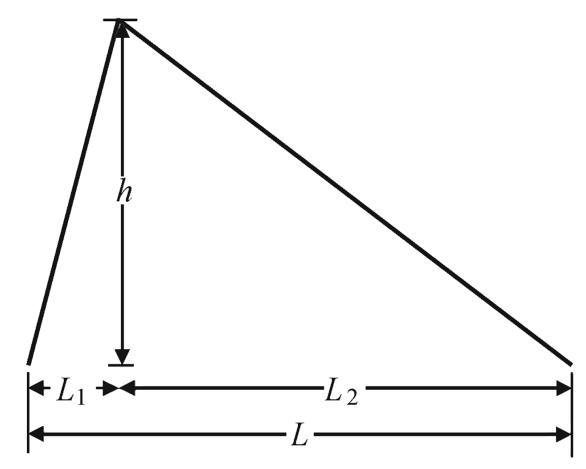

Fig. 4 Sketch of defining sandwave characteristic parameters

A, B and C, respectively. Next we will discuss sandwaves migration along the lines.

Symmetry Index The predicted positions in Octorber 2005 of the sandwaves along line P1 and line P3 are given in the Fig. 5 and the corresponding symmtry index for each sandwave also is indicated with histogram in the figure. It is clear that the calculating results are in good agreement with the observerd data. The symmetry indexes for each sandwave along P1 and P3 are negtive almost, with average -0.36 and -0.20 , respectively. From the symmetry index definition, the values mean the sandwaves in zone A and zone C moving toward left (southeast). By calculating the space of the sandwaves crests between July 2004 and Octorber 2005, the average speed is deduced $12.53 \mathrm{~m} / \mathrm{a}$ in zone A and $7.52 \mathrm{~m} / \mathrm{a}$ in zone $\mathrm{C}$, respectively. The results are very close to the measured values $12.05 \mathrm{~m} / \mathrm{a}$ in zone A and $7.84 \mathrm{~m} / \mathrm{a}$ in zone C. Comparing the symmetry indexes, we notice that the moving speed is proportional to the value of the symmetry index.

Steep Ratio Considering the relation of the sandwaves migration along P1 and P3 to the parameter of steep ratios by the right axis in Fig. 6, the steep ratios seem be weak relation with the migration speed unlike the symmetry index. The average value of steep ratio along P1 is about 0.065 and 0.039 along P3. As we mentioned in above section, the main difference between model 1 and model 2 is whether the bed slope contains factor $\lambda$. Thus in order to know the effect of the steep ratio on the sandwaves migration, we compare the two calculating results by model 1 and model 2 (Fig. 7). It is noticed that the steeper, the faster the sandwave moves. As the value of steep ratio is large than 0.05 , the effect of the steep ratio becomes apparent, as the ratio less than 0.05 , the effect can be neglected. In this case the model 1 can be adopted.

\section{CONCLUSIONS AND DISCUSSION}

Knaapen ${ }^{[22]}$ has proposed a relation of the migration speed $c$ with the sandwaves shape parameters based 
(a)

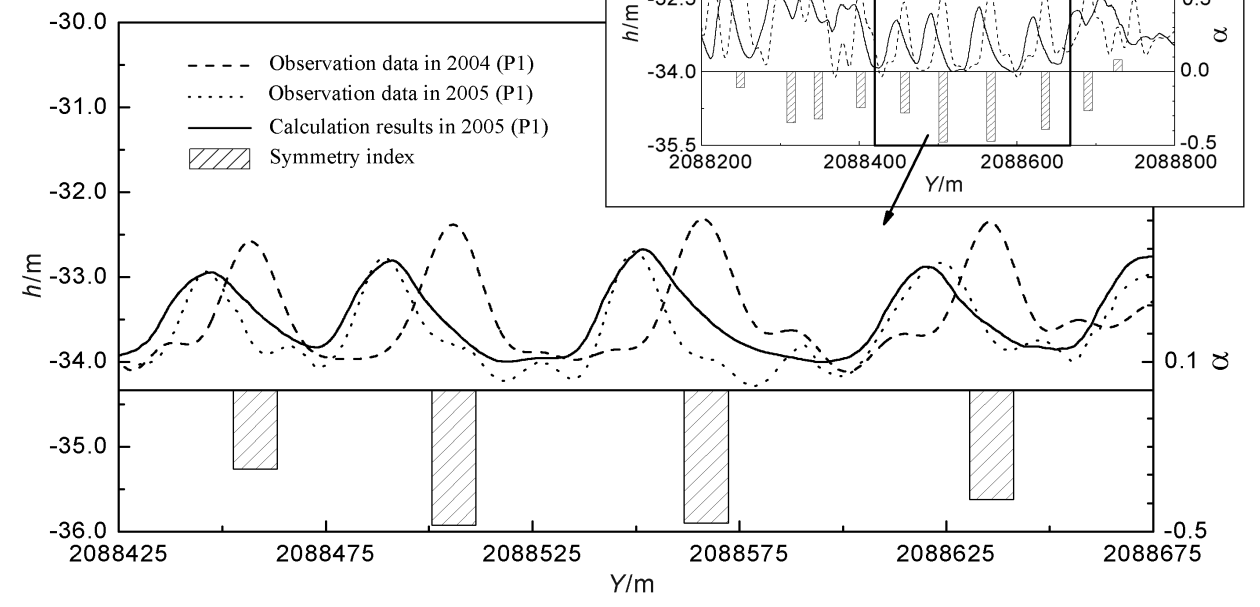

(b)

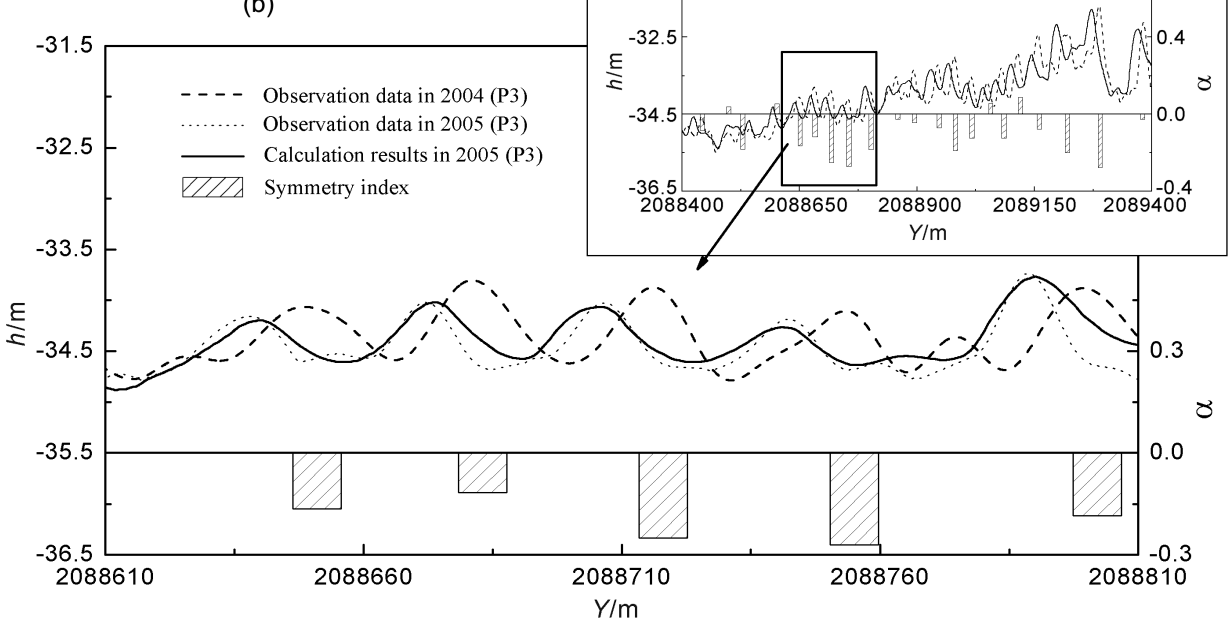

Fig. 5 Comparison the calculation with observed data regarding symmetry index as reference parameter (a) Zone A along line P1; (b) Zone C along line P3.

Dash line denotes the observed data in July 2004, dash dot line denotes the observation data in October 2005; solid line denotes the calculation result in Oct. 2005 by model II, and the histograms show the sandwaves symmetry $\alpha$.

on the observed data in southern bight of the North Sea and the English Channel, as follows:

$$
c=9.78 \times 10^{-4} \frac{L^{2}}{h} \alpha|\alpha| .
$$

By applying the above formula to the study area in this paper, the sandwaves migration speeds in zones $\mathrm{A}$ and zone $\mathrm{C}$ can be estimated to be $5 \mathrm{~m} / \mathrm{a}$ and $2 \mathrm{~m} / \mathrm{a}$, respectively. These values are much different from the survey results.

In addition we propose another formula developed by Japanese scholar Shinohara as ${ }^{[23]}$ :

$$
c=76.1\left(\frac{u_{*}^{2}}{g^{2} d h}\right)\left(\frac{\gamma_{\mathrm{w}}}{\gamma_{\mathrm{s}}-\gamma_{\mathrm{w}}}\right)\left(\frac{\tau_{\mathrm{e}}}{\tau_{0}}\right)^{2.5},
$$

where $\gamma_{\mathrm{s}}$ is the sediment specific gravity; $\gamma_{\mathrm{w}}$ is the water specific gravity; $u_{*}$ is the friction velocity near bottom; $\tau_{\mathrm{e}}$ is the effective bed shear stress; and $\tau_{0}$ is the average shear stress. According to hydrological data in the area, the average speed is estimated round $0.18 \mathrm{~m} / \mathrm{a} \sim 0.29 \mathrm{~m} / \mathrm{a}$, much less than the observations. 
(a)
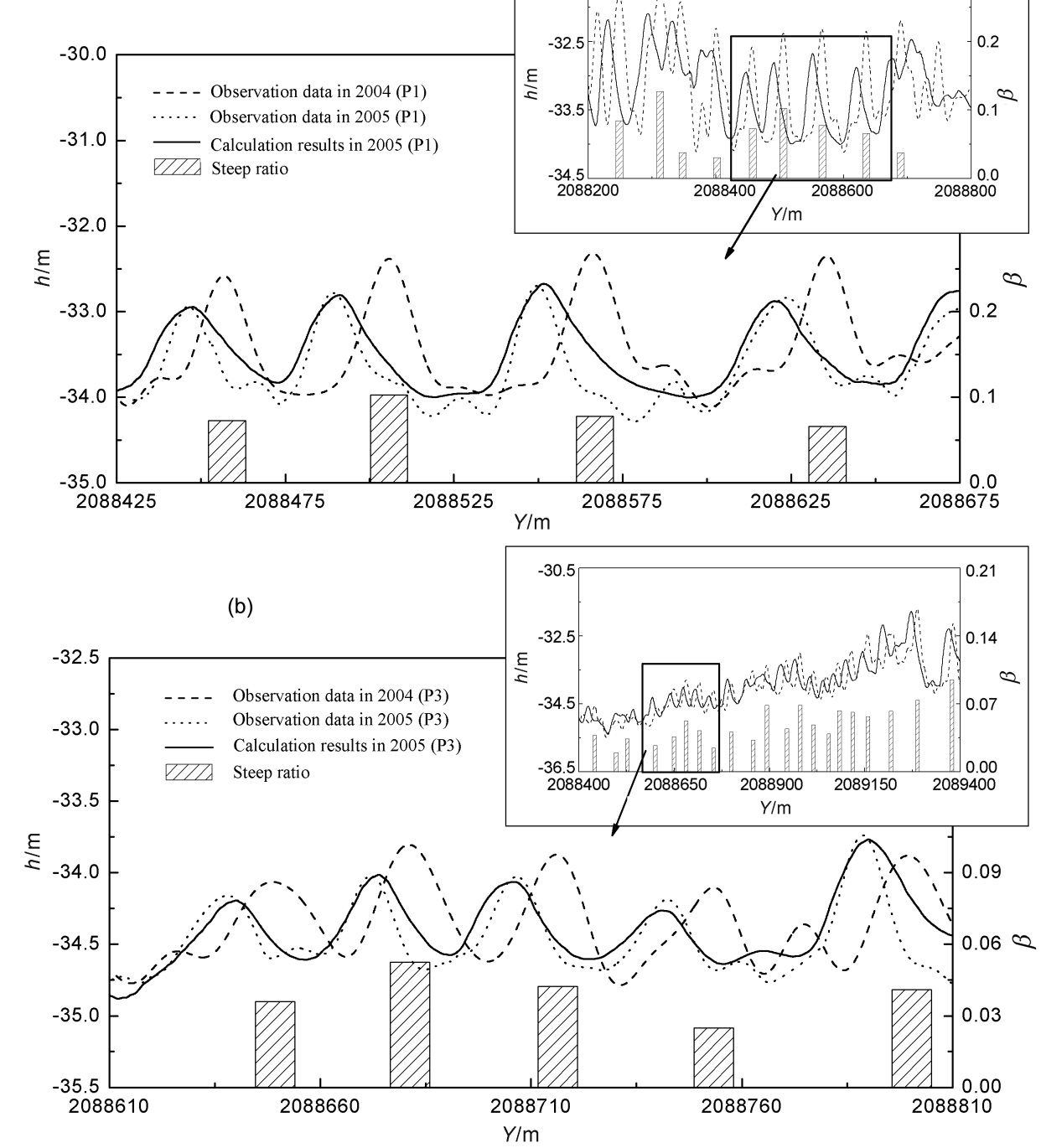

Fig. 6 Comparison the calculation with observed data regarding steep ratio as reference parameter

(a) Zone A along line P1; (b) Zone C along line P3.

Dash line denotes the observed data in July 2004, dash dot line denotes the observation data in October 2005;

solid line denotes the calculation result in Oct. 2005 by model II, and the histograms show the sandwaves symmetry $\beta$.

There are two reasons to explain the difference: first, the Knaapen's formula only considers the effect of sandwaves shapes; second, the Shinohara's formula is valid for the unidirection current. In reality, as we know, the sandwave migrations are dependent not only on the bottom characteristics but also on the circular tidal current and the wind-induced flow. Therefore only taking one factor (such as shape or flow) into account is unilateral and localized. The observed data indicate that the sand wave migrations are closely related to wind speeds and orientations ${ }^{[7]}$. At the Australia's Torres Strait, for example, the sandwaves moving directions reverse due to monsoon reversing every year. Thus now we will discuss the effects of wind-driven currents and sediments diameters.

In order to study the influence of monsoons, we consider two cases: i. only the tidal current; ii. joint action of the tidal current and the wind-driven current. The calculating results are plotted in Fig. 8. From Fig. 8a, we can estimate that the sandwave migration speeds by the tidal current are greater than that by the combining action with the discrepancy about 10 meters. The reason is because that there are two times of monsoon steering during the observational interval. In order to exmiane the effect of the sediment particle size, 


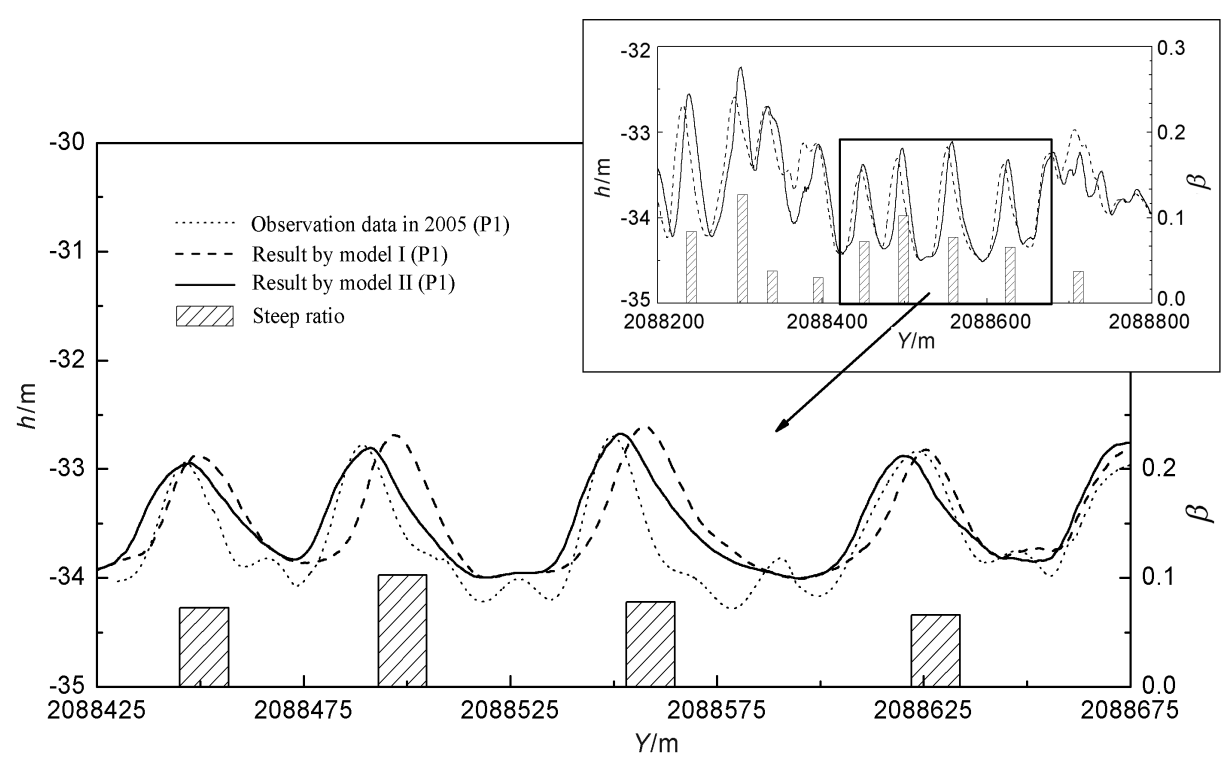

Fig. 7 Comparison calculation by different models

Dash dot line denotes the observation data in October 2005; solid line denotes the result by model II, dashed line by model I; and the histograms show the steep parameter $\beta$.
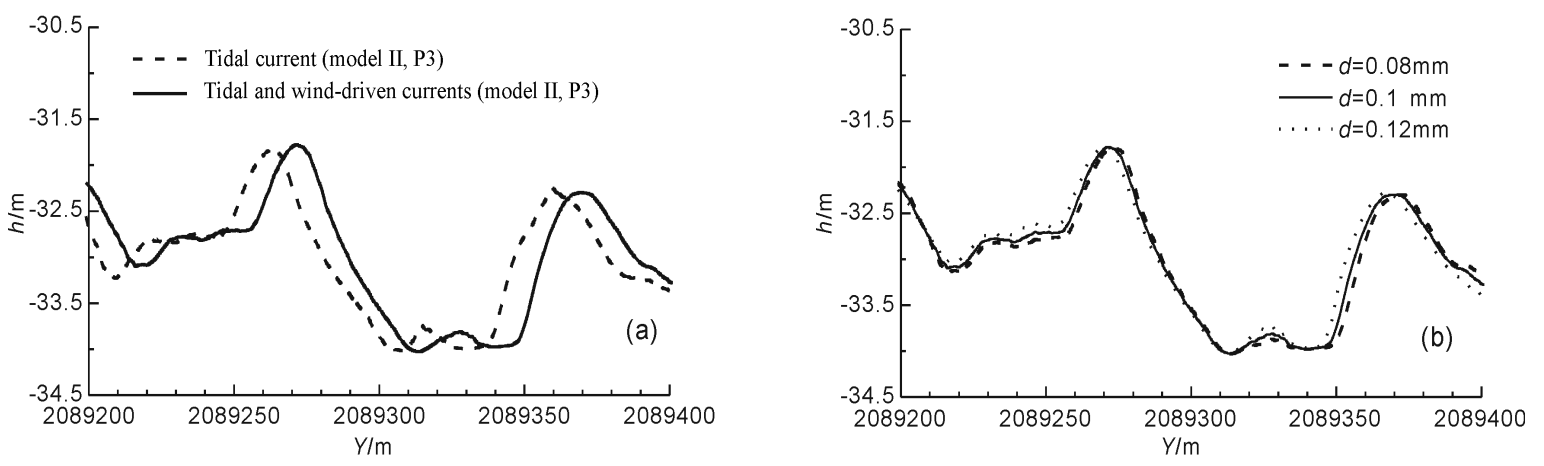

Fig. 8 The influence of wind-driven currents and sediment diameters to sandwaves migration

we calculate three sediment particle diameters $0.08 \mathrm{~mm}, 0.1 \mathrm{~mm}$ and $0.12 \mathrm{~mm}$. As can be seen from the Fig. $8 \mathrm{~b}$, even if the discrepancy of the diameters is just $0.04 \mathrm{~mm}$, the migrating distance differs almost 5 meters. It is concluded that the influences of the integrated hydro-geological situations on sandwave migration should be considered instead of only the effect of sandwave shape.

Up to now we can conclude that the predicting results are in good agreement with observed data in zones $\mathrm{A}$ and zone $\mathrm{C}$, respectively. But the calculating results in zone B do not match the observed data, especially the observed migration orientation is opposite to the predicting results (Fig. 9). In other words the direction of sandwaves migration seems not coincident with the residual current. It is beyond explained from an intuitive understanding. The phenomenon also has been mentioned by Lanckneus ${ }^{[2]}$ and Besio ${ }^{[5]}$. They also found that the migration orientations are not always consistent with residual currents and sometimes are opposite. Besio considered that the situation was due to the nonlinear effect induced by combined different tidal components. This explanation does not fit the zone B, for we have considered the coupling action of K1, O1 and M2. We think that some other special reason should be considered perhaps.

First, we inspect the sandwave migration trends in 2004 and 2005, respectively. It is found that the sandwaves in zones A and zone C have been moving to SE from 2004 to 2005, but the sandwaves in zone B moving to SE in 2004, and moving to NW in 2005. What causes such difference? The passing typhoons were different during 2004 and 2005. Then, we notice that the mean water depth in zone B is shallower $3 \mathrm{~m}$ than 


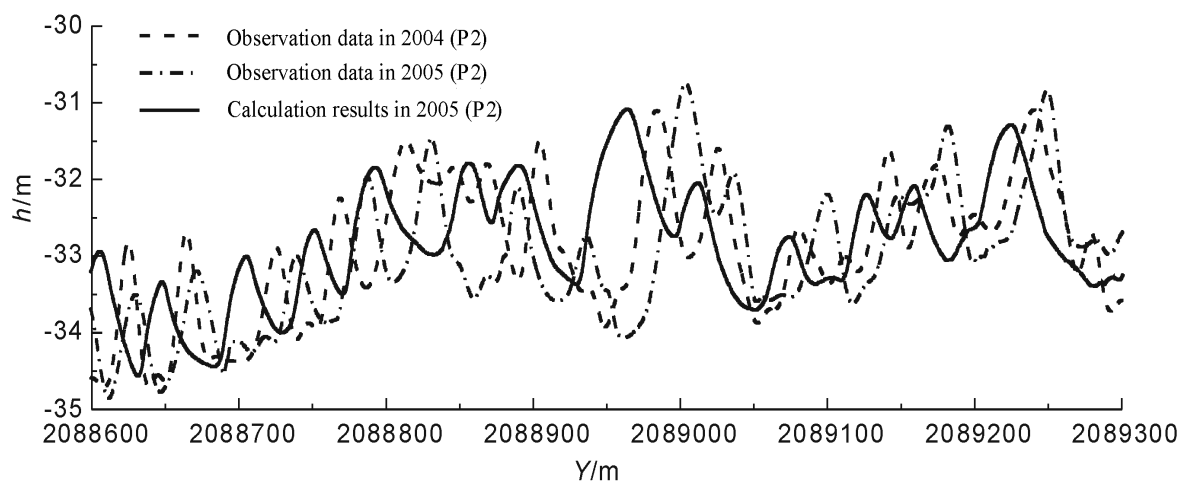

Fig. 9 Comparison calculation with observation data along line P2 in B zone

(Dash line denotes the observation data in July of 2004, dash dot line denotes the observation data in Oct. of 2005, solid line denotes the prediction result in Oct of 2005 by model two)

that in the zones A and zone $\mathrm{C}$, thus the sandwaves in zone B may be more sensitive to the typhoon, even the sediment whipped up by the storm wave. Typhoon may be the most important factor to cause the sandwave migration to reverse. The previous studies have figured out that the sandwaves migration direction is opposite to the mainstream direction under some wave-current ratio ${ }^{[25,26]}$. According to the weather data during 2004 and 2005, we count that there was no passing typhoon during 2004 and there were three passing typhoons (David, Vicente and Eagle) during 2005, especially the distance of the David typhoon to the study area was only about 20 kilometers.

In summary, the quasi-three dimension physical model for the sea in the northern gulf of the South China Sea can be used to predict the small-scale sandwave migration with bed load transport (region A and region C). But for the bedload and the suspended load co-existence, the model should be improved. Because of the linearly increasing trend of the storms in the South China Sea ${ }^{[27]}$, to consier the impact of storm surges for predicting sandwave migration will be very necessary in the near future.

\section{ACKNOWLEDGMENTS}

The research was supported by the National Natural Science Foundation of China (40776057) and the Project of CAS (KZCX2-YW-212-2) and the "863" Programs (2006AA09Z301) are gratefully acknowledged.

\section{REFERENCES}

[1] Whitehouse R J S, Damgaard J S, Langhorne D N. Sand waves and seabed engineering: application to submarine cables. Marine Sandwave Dynamics, International Workshop, March 23-24 2000, University of Lille 1, France Proceedings, Trentesaux A and Garlan T Ed: 227 234

[2] Morelissen R, Hulscher S J M H, Knaapen M A F, Németh A A, Bijker R. Mathematical modeling of sand wave migration and the interacting with pipelines. Coastal Engineering, 2003, 48: 197 209

[3] Thaiënne A G P D, Maarten G K. Processes controlling the dynamics of compound sad waves in the North Sea, Netherlands. Journal of Geophysical Research, 2005, 110, Fo4S10, dio:10.1029/2004JF000173

[4] Besio G, Blondeaux P, Frisina P. A note on tidally generated sand waves. Journal Fluid Mechanics, 2003, 485: $171 \sim 190$

[5] Besio G, Blondeaux P, Brocchini M, Vittori G. On the modeling of sand wave migration. Journal of Geophysical Research, 2004, 109(C4), doi:10.1029/2002JC001622C04018

[6] Besio G, Blondeaux P, Brocchini M, et al. The morphodynamics of tidal sand waves: a model overview. Coastal Engineering, 2008, 55: 657 670

[7] Richards K J, Taylor P A. A numerical model of flow over sand waves in water of finite depth. Geophysical Journal of the Royal Astronomical Society, 1981, 65: 103 128 
[8] Johns B, Soulsby R L, Chesher T J. The modelling of sand wave evolution resulting from suspended and bed load transport of sediment. Journal of Hydraulic Research, 1990, 28(3): 355 374

[9] Stansby P K, Zhou J G. Shallow water flow solver with non-hydrostatic pressure: 2D vertical plane problems. International Journal of Numerical Methods in Fluids, 1998, 28: 541 563

[10] Idier D, Astruc D. Numerical modelling of large-scale rhythmic bedforms in shallow water. River. Coastal and Estuarine Morphodynamics, IAHR, Obihiro, Japan, 2001. 565 574

[11] Hulscher S J M H., Tidal-induced large-scale regular bed form patterns in a three-dimensional shallow water model. Journal of Geophysical Research, 1996, 101(C9): 20727 20744

[12] Gerkema T. A linear stability analysis of tidally generated sand waves. Journal of Fluid Mechanics, 2000, 417: $303 \sim 322$

[13] Komarova N L, Hulscher S J M H. Linear instability mechanics for sand wave formation. Journal of Fluid Mechanics, 2000, 413: $219 \sim 246$

[14] Nemeth A A, Hulscher S J M H, De Vriend H J. Modelling sand wave migration in shallow shelf seas. Continental Shelf Research, 2002, 22: 2795 2806

[15] Veen H H V D, Hulscher S J M H, Knaapen M A F. Grain size dependency in the occurrence of sand waves. Ocean Dynamics, 2006, 56: 228 234

[16] Passchier S, Kleinhans M G. Observations of sand waves, megaripples, and hummocks on the Dutch coastal area and their relation to currents and combined flow conditions. Journal Geophysics Research, 2005, 110, F04S15, doi:10.1029/2004JF000215

[17] Zhou S M, Lin M. Influence on migration of sand waves. The 16th International Offshore and Polar Engineering Conference, San Francisco, California, USA. 2006. 527 532

[18] Lin M, Li Y, Zou S M. Investigation the dynamic models of the migration of varying scale sand-waves. Proceedings of the 21st National Conference on Hydrodynamics (in Chinese), 2008. 859 864

[19] Xia H Y, Li S H, Shi M C. A 3-D numerical simulation of wind-driven currents in the Beibu Gulf. Acta Oceanologica Sinica (in Chinese), 2001, 23(6): 11 23

[20] Cao D M, Fang G H. A numerical model of the tides and the tidal currents in Beibu Bay. Oceanologia et Limnologia Sinica (in Chinese), 1990, 21(2): 105 113

[21] Cookman J L, Flemings P B. STORMSED1.0: hydrodynamics and sediment transport in a 2-D, steady-state, wind and wave-driven coastal circulation model. Computers Geosciences, 2001, 27: 647 674

[22] Knaapen M A F. Sandwave migration predictor based on shape information. Journal of Geophysical Research, 2005, 110, F04S11, doi:10.1029/2004JF000195

[23] Shinohara K, Tsubaki T, On the characteristics of sand waves formed upon the bed of the open channels and rivers. Rep. Res. Inst. Applied Mech. Kyushu Univ. Japan, 1959, 7(25): 15 45

[24] Lanckneus J, De Moor G. Present-day evolution of sand waves on a sandy shelf bank. Oceanologia Acta, 1991, SP-11: $123 \sim 127$

[25] Lin M, Yuan Z D. Estimating the speed of cross shore sand waves. The 16th International Offshore and Polar Engineering Conference, San Francisco, California, USA, 2006. 717 722

[26] Lin M, Yuan Z D. Investigation of characteristics of fluid field over wavy beds under oscillatory flow. Chinese J. Geophys. (in Chinese), 2005, 48(6): 1526 1534

[27] Wang J B, Qian W H. Statistic analysis of tropical cyclone impact on China mainland during the last half century Chinese. Chinese J. Geophys. (in Chinese), 2005, 48(5): 992 999 